\title{
TIME-SPACE ANALYSIS OF TRANSPORT SYSTEM USING DIFFERENT MAPPING METHODS
}

\author{
Péter Ficzere ${ }^{1}$, Zita Ultmann², Ádám Török ${ }^{3}$ \\ ${ }^{1}$ Dept of Vehicle Parts and Drives, Budapest University of Technology and Economics, Hungary \\ ${ }^{2}$ Dept of Geodesy and Surveying, Budapest University of Technology and Economics, Hungary \\ ${ }^{3}$ Dept of Transport Economics, Budapest University of Technology and Economics, Hungary
}

Submitted 22 April 2013; 20 accepted August 2013; first published online 9 May 2014

\begin{abstract}
Transport systems exist within at least two types of space. One is the apparent geographic space, but equally important is the time-space implied by the travel time relations created by the system. Differences between the geographic and time-spaces are properties induced by the transport system. Methods for time-space transformations of geographic space to explore visualize and analyse transport systems were initially developed in the 1960s and 1970s but due to the low computational capacity not evolved yet. However, these methods have not been pursued beyond this initial flurry of research activity, most likely due to the difficulties associated with handling and processing huge amount of digital geographic data. This paper presents a case study of the transformation possibilities and particularly the usage of non-affine transformations of maps - Rubber-Sheet Method (RSM) - using a typical GIS software called ArcView in order to analyse the current status and development possibilities of the Hungarian railway system.
\end{abstract}

Keywords: railway transport; analysis; deformation; modelling; transport system development.

Reference to this paper should be made as follows: Ficzere, P.; Ultmann, Z.; Török, Á. 2014. Time-space analysis of transport system using different mapping methods, Transport 29(3): 278-284.

http://dx.doi.org/doi:10.3846/16484142.2014.916747

\section{Introduction}

It is very common to build distorted graphics in order to highlight relevant information in different cases, for example the $\mathrm{CO}_{2}$ emission on Earth by country (Fig. 1). The higher the $\mathrm{CO}_{2}$ emission the larger the distortions are.

Authors have investigated of usage of distorted geographical maps in order to reveal the distortion of travel time. Understanding the travel time relationships induced by a transport system can be crucial for assessing its performance. Transport systems attempt to improve the efficiency of trading time for space when moving between geographic locations. Greater time efficiency for movement can enhance individuals' accessibilities to activities and resources by freeing more time for travel and activity participation. Conversely, less time efficiency in geographic movement can reduce accessibility through the consumption of scarce temporal resources that could otherwise be used for travel and activity participation (Hägerstrand 1970). Spatial variations and patterns in these travel time relationships can help transport analysts and planners understand relative differences in system performance, guiding the plan- ning, design and deployment of transport infrastructure and services towards efficient and equitable outcomes. The travel time relationships induced by a transport system imply a time-space connection where relative locations and proximity relationships can differ from those in geographic space. As with geographic space, mapping and spatial analysis of time-spaces can be illuminating. Time-space maps can provide a synoptic visual summary of the travel time relationships in a given environment, indicating areas where the transport system is
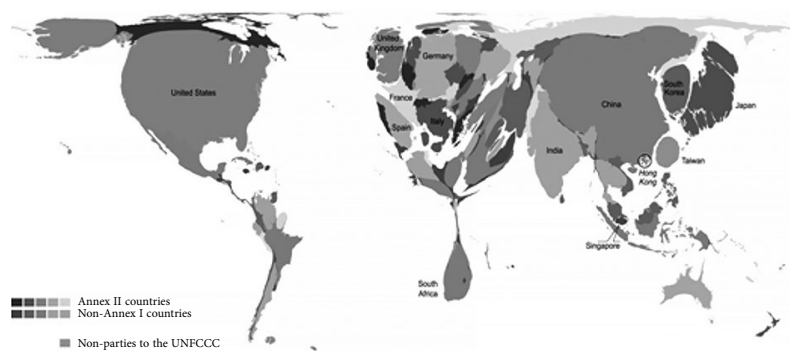

Fig. 1. Total $\mathrm{CO}_{2}$ emissions (Bournay 2008)

Corresponding author: Ádám Török

E-mail: atorok@kgazd.bme.hu

Copyright ๑ 2014 Vilnius Gediminas Technical University (VGTU) Press

http://www.tandfonline.com/TRAN 


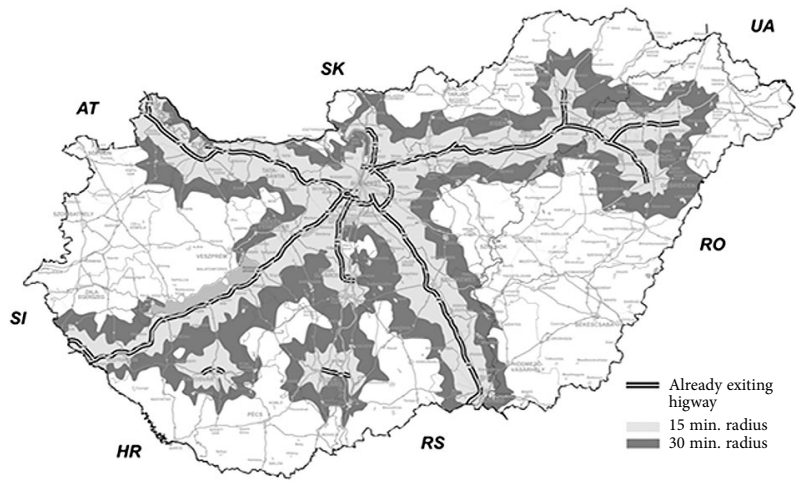

Fig. 2. Accessibility of highways (source: KTI - Institute for Transport Sciences, http://www.kti.hu/uploads/images/ Trends6/Masodik/2-150.jpg)

performing well and other areas where it is inefficient. Also, since induced travel time relations are central to transport systems, spatial analysis of time-space can be more meaningful than analysis of geographic space in understanding transport system performance (Ahmed, Miller 2007). Several attempts were done even in Hungary for travel time based maps (Fig. 2).

The aim of authors was to build up a distorted map that significantly shows the changes in travel time compared to geographical map. Authors have investigated the different kind of transformations of railway infrastructure maps in order to gain new information on infrastructure (e.g. rate of centralisation, missing links, etc.). The basic Hungarian railway infrastructure has been examined but the described method can be adapted to other transport modes and other countries as well. Nowadays railway reaches its second 'goldenage', at European level more and more funds are available for railway investments in order to increase efficient usage of railroad (Gašparík, Zitrický 2010). A method had been investigated which is able not only to analyse the reduction of travel time as a social benefit for the current system but is capable of estimating the social benefits of future investments as well.

\section{Methodology}

Mapping time-spaces has a long history in spatial analysis. Research dates back to pioneering work in the 1960s by Bunge (1960) and Tobler (1961). Cartographic transformations to generate time-spaces reached a peak in the 1970s with the work of researchers such as Marchand (1973), Forer (1974, 1978), Ewing, Wolfe (1977), Clark (1977), Muller (1978). Despite the efforts of these and subsequent researchers, key issues surrounding time-space mapping remain unresolved. Inconclusive results regarding the nature of time-spaces and their structure probably result from the state of key transformation techniques such as Multi-Dimensional Scaling (MDS) and map comparison techniques. There are different ways to establish the connection between the two, different type of maps (the travel time and the geographical map) such as in case of Berta and Török (2010). The easiest and most accurate way was to find some control points (significant points, which can be easily find on both of the two maps) to determine the mathematical relationship. In our case 34 different points were given in the transformations (all county seats and mayor border crossing points for passenger train transport). The corresponding travel time data were collected between them and two different matrices were built in Microsoft Excel spreadsheet (Figs 3 and 4).

The travel time can act as distance in a mathematical sense, and a symmetric 'travel' time distance matrix between $m$ points can be developed:

$$
D=\left\{d_{i j}\right\}, i, j=1 \ldots n,
$$

where: $D$ is the overall distance matrix (symmetric, square matrix); $d_{i j}$ is the travel time distance between city $i$ and $j$.

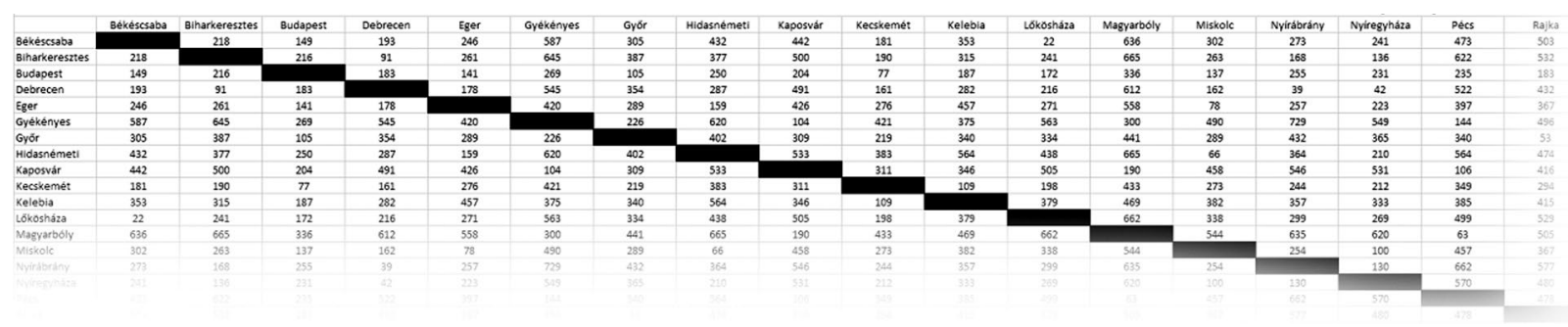

Fig. 3. Travel time [min] between the 34 cities - part of the travel time matrix (source: own research based on timetables)

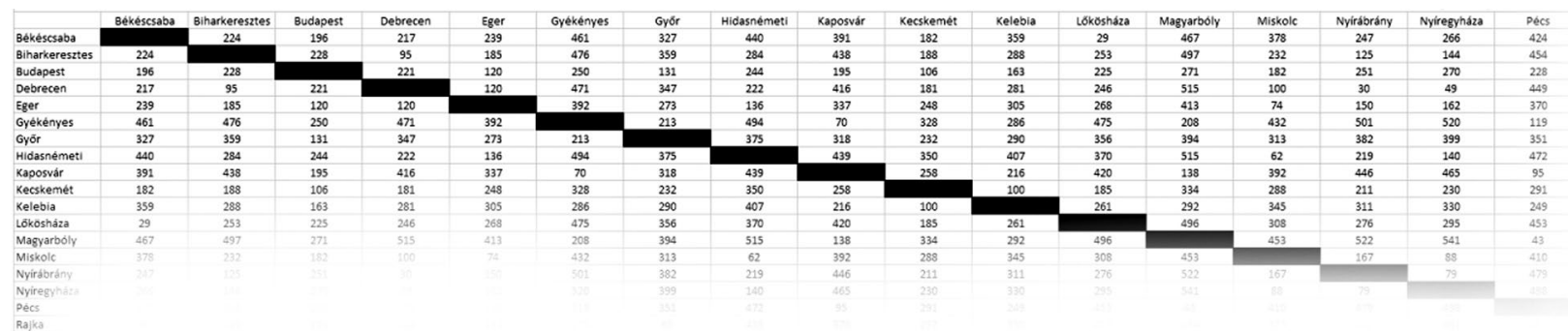

Fig. 4. Distance $[\mathrm{km}]$ between the 34 cities - part of the distance matrix (source: own research) 
This matrix is a symmetric one, because it is assumed that $d_{A B}=d_{B A}$ and if $A=B$ then $d_{A B}=0$. Authors are assumed that in railway transport the distances are similar there and back. Mathematically travel time is behaving like a distance function so it can also be a basis of a graph. In order to visualise the two different graphs from the distances (geographical and time distances) the matrices were converted to SPSS (Statistical Package for Social Sciences, http://www.ibm.com/software/analytics/spss) statistical analysing software. In the Euclidean space, the distance between two points is given by the Euclidean distance (2-norm distance). In 2 dimensions, the minimum distance between two points is the length of the line segment between them. This gives us the shortest straight distance between the two points. Authors had to face the fact that the 2-norm 'Cartesian' distance is not describing correctly the situation, because the railway tracks are not on the 'shortest' path. That is the reason why authors have changed the 'Cartesian' distance to 'travel' distance. 'Travel' distance describes the distance between city $A$ and $B$, by the route between them. To build up a graph from distances (geographical and time based) the necessary relative coordinates of the cities were calculated as vertices of the graphs. MDS were used in SPSS which is a set of related statistical techniques often used in data visualization. An MDS algorithm starts with a matrix (matrix of distances in this case), and then assigns a 'location' of each vertice suitable for graphing:

$\underline{D}=\left|\begin{array}{ccc}0 & \left(\sqrt{\left(x_{j}-x_{1}\right)^{2}+\left(y_{j}-y_{1}\right)^{2}}\right) & \left(\sqrt{\left(x_{m}-x_{1}\right)^{2}+\left(y_{m}-y_{1}\right)^{2}}\right) \\ \left(\sqrt{\left(x_{1}-x_{i}\right)^{2}+\left(y_{1}-y_{j}\right)^{2}}\right) & 0 & \left(\sqrt{\left(x_{m}-x_{i}\right)^{2}+\left(y_{m}-y_{i}\right)^{2}}\right) \\ \left(\sqrt{\left(x_{1}-x_{m}\right)^{2}+\left(y_{1}-y_{m}\right)^{2}}\right) & \left(\sqrt{\left(x_{j}-x_{m}\right)^{2}+\left(y_{j}-y_{m}\right)^{2}}\right) & 0\end{array}\right|$.

As it can be seen there is direct bijective relation between Eq. (1) and Eq. (3) so relation (3) describes the matrix of Euclidean distances, based on the relative coordinates of cities (vertices) in the graph. This is the method how the computer calculates the place of vertices or cities compared to other vertices or cities. The output of the MDS method in SPSS are the relative coordinates of cities in case of travel time distances (see Fig. 5, 2nd and 3rd columns). The graphs were visualized in Microsoft Excel spreadsheet (Fig. 5).

Similar method had been used by Dusek (2010) but at the end the calculations and graphical representation was conducted by Darcy 2.0 software. Therefore only Rubber-Sheet Method (RSM) was used for 23 nods by Dusek. Since then the development of computational science made it possible to run the RSM with 34 nodes. Authors have investigated the possibilities of linear and quadratic transformation. Finally in this method the graphs (geographical and travel time based) were saved in graphical (jpeg) format in order to be able to import in ArcView 10 to perform geographical information analysis. It is a typical GIS software, distributed by ESRI ( $h t t p: / / w w w$. esri.com). The software gave three possible ways to create the mathematical connection between the two point clouds. The first and most commonly used is the affine transformation. With an affine transformation the transformed coordinates can be derived as a linear function of the original coordinates. It is a transformation that preserves angles and changes all distances in the same ratio, called the ratio of magnification. That is a typical linear transformation, which means that after transformation linear is to remain linear as it was before (Detreköi, Szabó 1995). The main equation can be found here:

$$
\begin{aligned}
& X^{t}=P_{x}^{a}+A_{11}^{a} X+A_{12}^{a} Y ; \\
& Y^{t}=P_{y}^{a}+A_{21}^{a} X+A_{22}^{a} Y,
\end{aligned}
$$

where: $T\left(X^{t}, Y^{t}\right)$ - transformed coordinates (based on geographical distances); $C(X, Y)$ - original coordinates (based on travel time); $\left[\begin{array}{ll}A_{11}^{a} & A_{12}^{a} \\ A_{21}^{a} & A_{22}^{a}\end{array}\right]$ - transformation matrix of affine; $\left\{\begin{array}{cc}P_{x}^{a} & P_{y}^{a}\end{array}\right\}$ - vector of shifting.

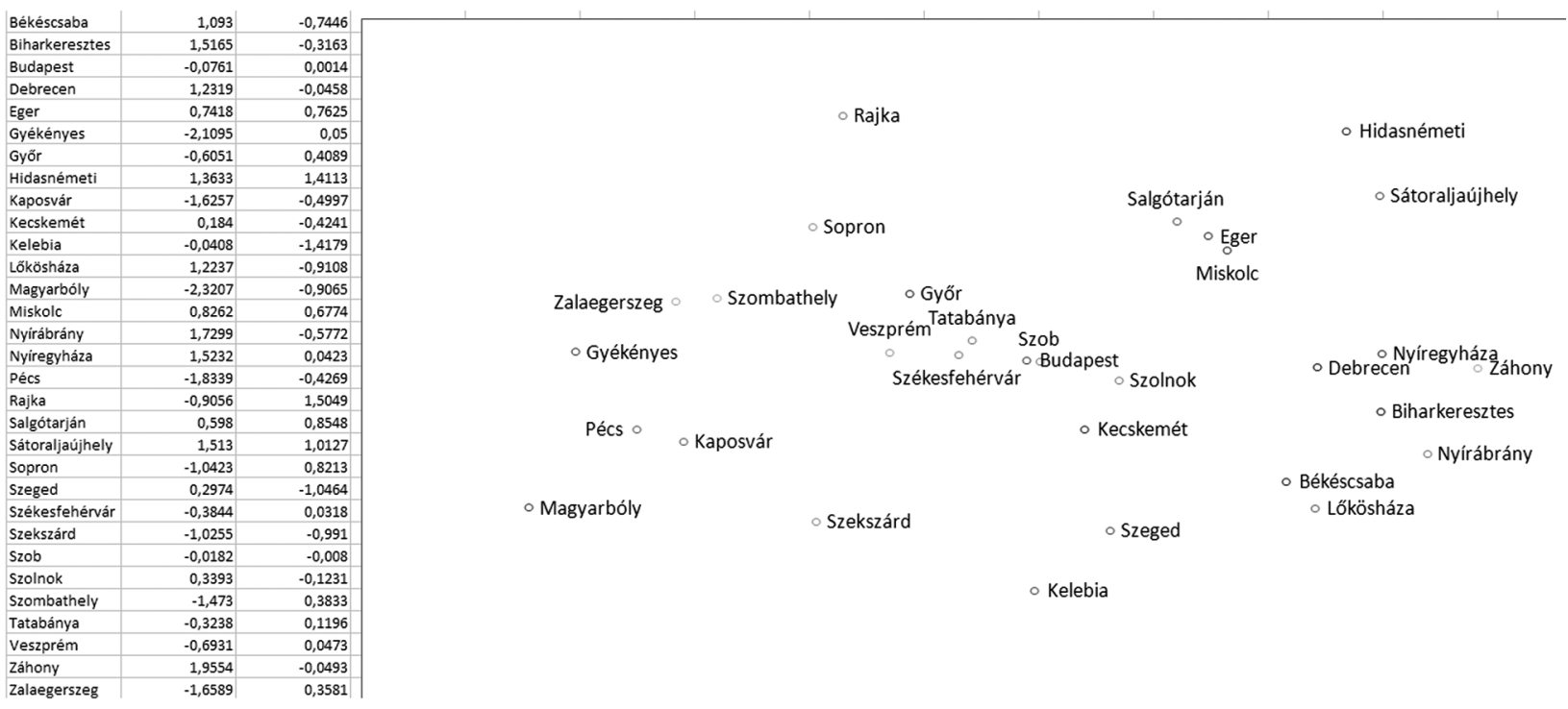

Fig. 5. Relative coordinates and visualisation of travel time graph (source: own research based on timetables) 
Increasing the power of the transformation might give better result between the two databases, so the second way became the quadratic transformation. The main connections are the following:

$$
\begin{aligned}
& X^{t}=P_{x}^{q}+A_{11}^{q} X+A_{12}^{q} Y+A_{13}^{q} X^{2}+A_{14}^{q} X Y+A_{15}^{q} Y^{2} ; \\
& Y^{t}=P_{y}^{q}+A_{21}^{q} X+A_{22}^{q} Y+A_{23}^{q} X^{2}+A_{24}^{q} X Y+A_{25}^{q} Y^{2},
\end{aligned}
$$

where: $T\left(X^{t}, Y^{t}\right)$ - transformed coordinates (based on geographical distances); $C(X, Y)$ - original coordinates (based on travel time); $\left[\begin{array}{ccccc}A_{11}^{q} & A_{12}^{q} & A_{13}^{q} & A_{14}^{q} & A_{15}^{q} \\ A_{21}^{q} & A_{22}^{q} & A_{23}^{q} & A_{24}^{q} & A_{25}^{q}\end{array}\right]$ transformation matrix of affine; $\left\{\begin{array}{cc}P_{x}^{a} & P_{y}^{a}\end{array}\right\}$ - vector of shifting.

The third one is the rubber-sheet transformation. It is based on a 'flexible surface' in which the original map points are not uniformly transformed. The rubbersheet transformations can be implemented partly as well - they are usually called patch - so the map can be divided into regions and every part can have of its own transformation equation. The equations need to satisfy the continuity condition of parts, namely the first and second derivates supposed to be the same in the connecting points. Therefore the residuals are always zero. The main equation cannot be described in a closed form, it vary locally. On Fig. 6 the summary of the technological steps can be seen.

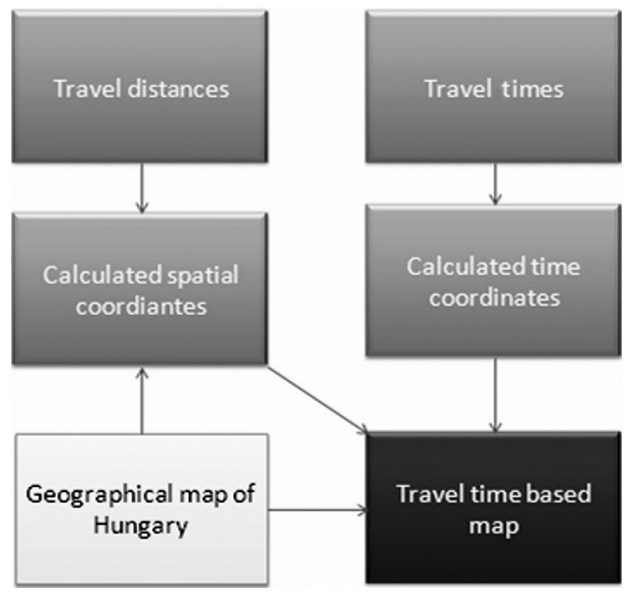

Fig. 6. Description of method (source: own research)

The described method cannot be inverted as it makes no sense from time-map to build up a spatial map and it is independent from the method of transformation.

\section{Results}

The transformation matrices were used to modify the geographical map in order to investigate the railway travel time in Hungary (Fig. 7). The input dataset of travel time can vary through time (summer/winter period or day/night). The input dataset were based on the average travel time from schedule.
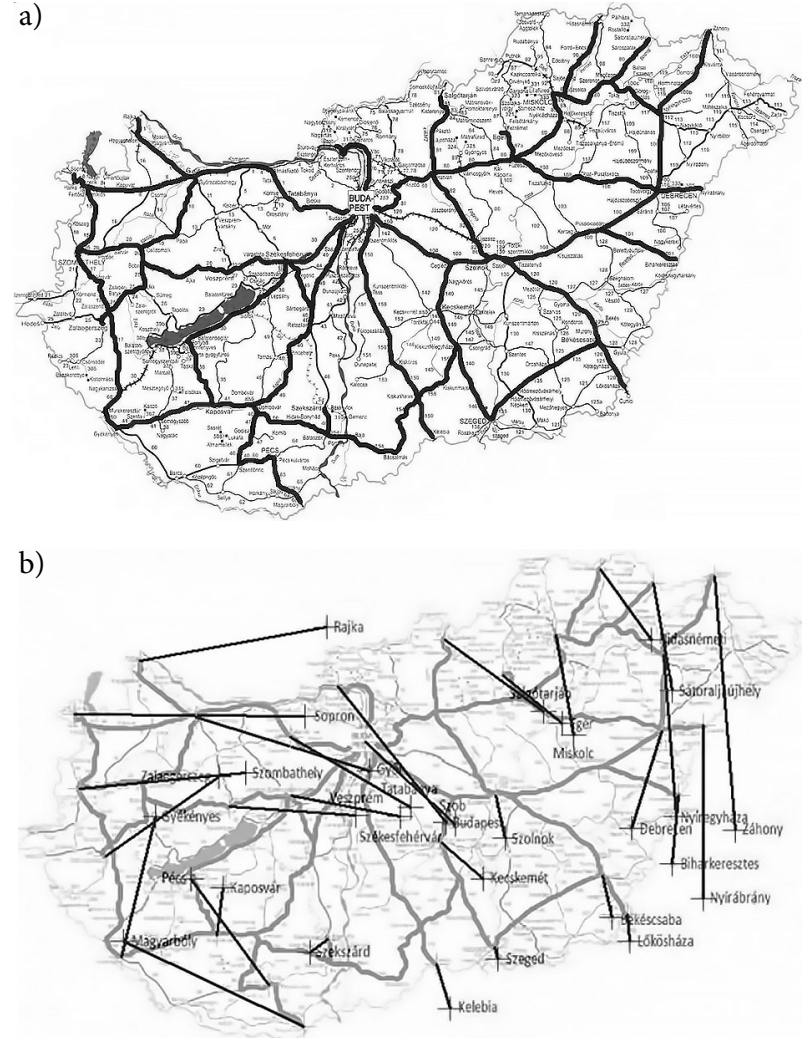

Fig. 7. Railway tracks (a) at original unmodified geographical map and residual vectors (b) (source: own research)

The three different transformations require a different amount of significant points the first two are easier because the affine needs at least 3 the quadratic needs at least 6 control points. Due to the local solutions of rubber-sheet transformation it is not possible to give an exact amount of significant points. In our case 34 different points were given in the transformations (all county seats and mayor border crossing points for passenger train transport), which at the first two cases are more than the minimum, so these methods are easy to analyse. ArcView has a built in Least Square Algorithm (LSA) to determine the elements of the different transformation matrixes and the Root Mean Square (RMS), which refers to a total distance of residual vectors, is also computable. Preliminary results of this model had already been published, but since then the model and the statistical analysis are developed (Ficzer et al. 2011). The main equation of the Total RMS Errors (TRMSE) is the following:

$$
\text { TRMSE }=\sqrt{\sum_{i=1}^{34} r_{i}^{2}}
$$

where:

$$
r_{i}=\sqrt{\left(A\left(X_{i}\right)-X_{i}^{t}\right)^{2}+\left(A\left(Y_{i}\right)-Y_{i}^{t}\right)^{2}}
$$

where: $T\left(X^{t}, Y^{t}\right)$ - transformed coordinates (based on geographical distances); $C(X, Y)$ - original coordinates (based on travel time); $\left[\begin{array}{c}A(X) \\ A(Y)\end{array}\right]$ - transformation matrix (determined using the LSA). 

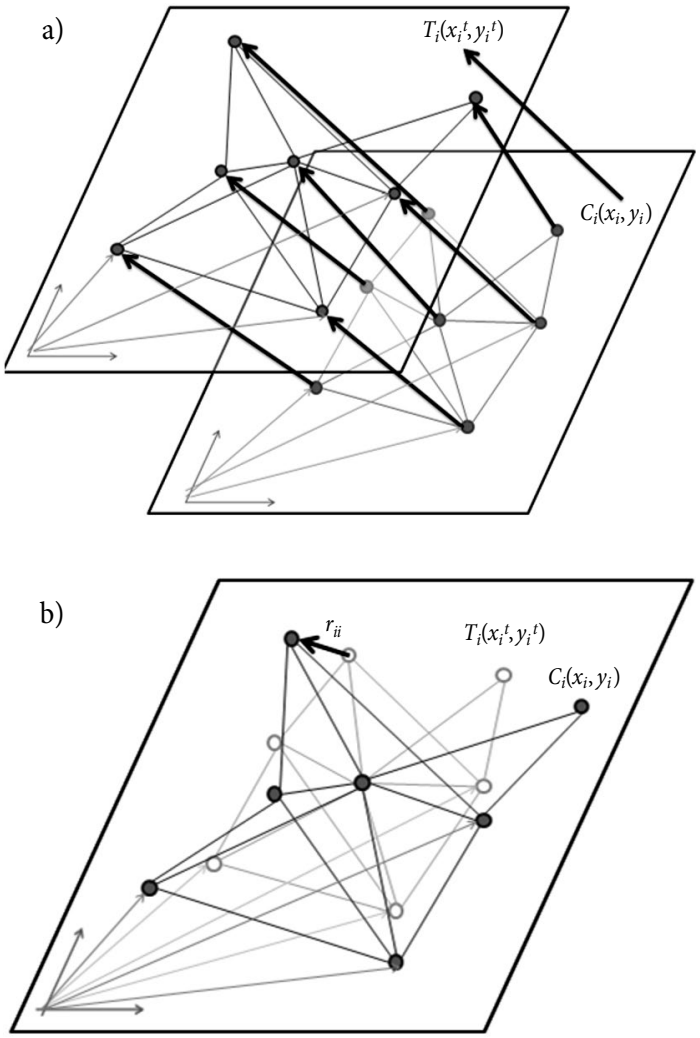

Fig. 8. Representation of residual vectors (source: own research)

The meaning of the RMS is illustrated on the Fig. 8. As it can be seen from Fig. 9 only rotation was used as linear transformation to get the control points covered. The statistical results shows that the TRMSE is quite high therefore it needs to be decreased. For this reason authors have increased the power of transformation in order to get more suitable covering and lower error.

As it can be seen from Fig. 10 linear elements were distorted due to the quadratic transformation to parallelogrammic elements. The statistical result shows that the TRMSE is smaller in the quadratic case as compared to the linear but it is still significant and therefore it needs to be decreased.

Further on authors have not increased the power of the transformation for better approximation but have chosen another way of approximation: the transformation called RSM, which provides zero TRMSE by definition as using different distortion matrices for different locations. 34 particular locations had been established by the computer around the 34 cities and made perfect covering with 0 error. The rubber-sheeting based on planar affine transformation (White, Griffin 1985; Saalfeld 1985) has been very popular as a possible and effective map conflation technique (Doytsher 2000). This techniques were used as the rubber-sheeting of historical maps (Fuse et al. 1998; Shimizu et al. 1999). More recently its implementations have been reported by Niederoest (2002). The result of rubber-sheet transformation in this case can be seen in Fig. 11.

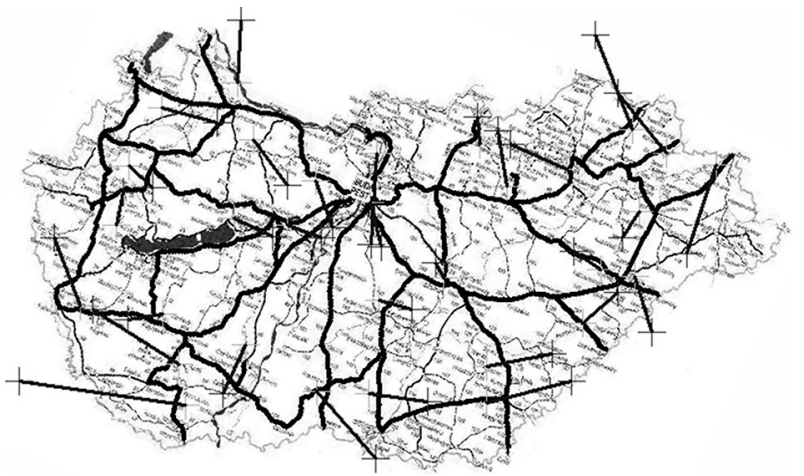

Fig. 9. Linear transformation of railway tracks by travel time and the stress vectors (total sum of residual vectors $=91.84895)$ (source: own research)

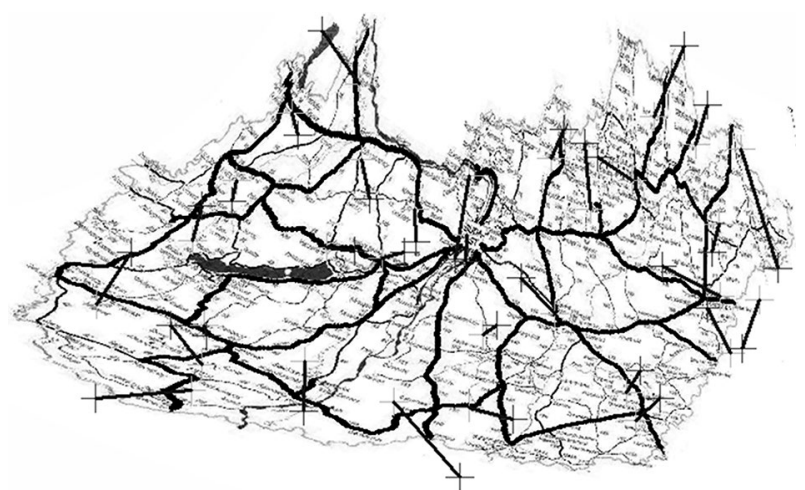

Fig. 10. Quadratic transformation of railway tracks and stress vectors (total sum of residual vectors $=72.93283$ ) (source: own research)

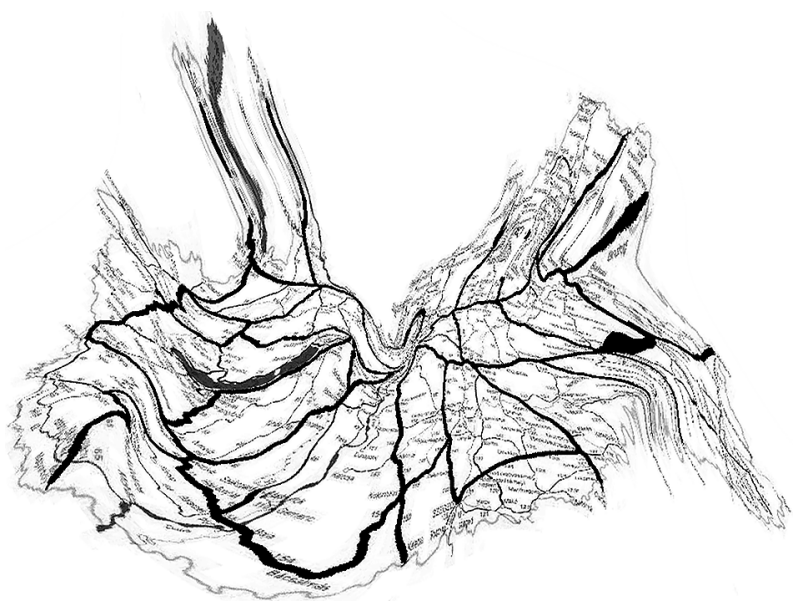

Fig. 11. Rubber-sheet transformation of railway tracks by travel time (source: own research)

\section{Conclusions}

The result of investigation (Fig. 11) clearly shows the centralised situation of the capital Budapest and the travel time distortion.

You can see on Fig. 12 that dark grey background nowadays is located in our neighbourhood countries. The remaining topology is evidently centralised: the 


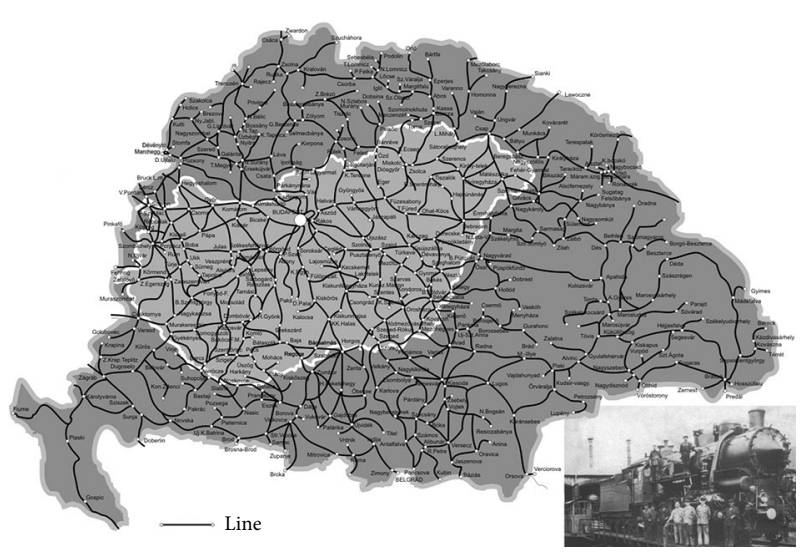

Fig. 12. Hungarian railway network in 1920 and now

(Heinczinger 2011)

core is Budapest. The time map reveals the missing links since nowadays they belong to the neighbourhood countries. Mostly radial directions were found in Hungary. Authors have found that radial track should be developed and should be extended by side lanes. This results only based on travel times not on passenger counts. The linear and the quadratic models had huge errors therefore the results that were gained from these models were not used for the investigation which cover the whole country. But these methods could give a good base for local investigations and optimalisations (e.g. local bus route planning).

As a result it can be stated that map distortion is fully functioning as a tool of railway infrastructure investigation. New and additional information can be derived from time maps as analytic tool of visualization.

\section{Acknowledgements}

The authors are grateful to the reviewers for their remarks and suggestions, this paper would never have been completed without their support.

This work is connected to the scientific program of the 'Development of quality-oriented and harmonized $\mathrm{R}+\mathrm{D}+\mathrm{I}$ strategy and functional model at BME' and 'Modelling and multi-objective optimization based control of road traffic flow considering social and economical aspects' project.

These projects are supported by the New Szechenyi Development Plan (Project ID: TÁMOP-4.2.1/B-09/1/ KMR-2010-0002) and by program CNK 78168 of OTKA.

This paper is supported by Bólyai János Research fellowship of HAS (Hungarian Academy of Science).

The work reported in the paper has been developed in the framework of the project 'Talent care and cultivation in the scientific workshops of BME' project.

This project is supported by the grant TÁMOP4.2.2.B-10/1-2010-0009.

\section{References}

Ahmed, N.; Miller, H. J. 2007. Time-space transformations of geographic space for exploring, analyzing and visualizing transportation systems, Journal of Transport Geography 15(1): 2-17. http://dx.doi.org/10.1016/j.jtrangeo.2005.11.004

Berta, T.; Török, Á. 2010. Travel time reduction due to infrastructure development in Hungary, Promet - Traffic \& Transportation 22(1): 23-28. http://dx.doi.org/10.7307/ptt.v22i1.161

Bournay, E. 2008. Total $\mathrm{CO}_{2}$ Emissions. GRID-Arendal. Arendal, Norway. Available from Internet: http://www.grida.no/ graphicslib/detail/total-co2-emissions_13ca

Bunge, W. 1960. Theoretical Geography. A thesis submitted in partial fulfilment of the requirements for the degree of doctor of philosophy. University of Washington. $189 \mathrm{p}$.

Clark, J. W. 1977. Time-distance transformations of transportation networks, Geographical Analysis 9(2): 195-205. http://dx.doi.org/10.1111/j.1538-4632.1977.tb00573.x

Detrekői, Á.; Szabó, G. 1995. Bevezetés a térinformatikába. Nemzeti Tankönyvkiadó, Budapest. 252 o. (in Hungarian).

Doytsher, Y. 2000. A rubber sheeting algorithm for non-rectangular maps, Computers \& Geosciences 26(9-10): 10011010. http://dx.doi.org/10.1016/S0098-3004(00)00023-6

Dusek, T. 2010. Comparison of air, road, time and cost distances in Hungary, in Proceedings of the 50th Congress of the European Regional Science Association, 19-23 August 2010, Jönköping, Sweden. Paper 1025. 13 p. Available from Internet: http://www-sre.wu.ac.at/ersa/ersaconfs/ersa10/ ERSA2010finalpaper1025.pdf

Ewing, G. O.; Wolfe, R. 1977. Surface feature interpolation on two-dimensional time-space maps, Environment and Planning A 9(4): 429- 437. http://dx.doi.org/10.1068/a090429

Ficzer, P.; Ultmann, Z.; Török, Á. 2011. An analysis of a transport system using non-affine transformations, International Journal for Traffic and Transport Engineering 1(3): 142-148.

Forer, P. 1978. A place for plastic space?, Progress in Human Geography 2(2): 230-267. http://dx.doi.org/10.1177/030913257800200203

Forer, P. 1974. Space through time: a case study with NZ airlines, in Cripps, E. L. (Ed.). Space-Time Concepts in Urban and Regional Models, 22-45.

Fuse, T.; Shimizu, E.; Morichi, S. 1998. A study on geometric correction of historical maps, The International Archives of the Photogrammetry, Remote Sensing and Spatial Information Sciences 32(5): 543-548.

Gašparík, J.; Zitrický, V. 2010. A new approach to estimating the occupation time of the railway infrastructure, Transport 25(4): 387-393.

http://dx.doi.org/10.3846/transport.2010.48

Hägerstrand, T. 1970. What about people in Regional Science?, Papers of the Regional Science Association 24(1): 6-21. http://dx.doi.org/10.1007/BF01936872

Heinczinger, M. 2011. Analysis of the relation of transport and society, transport policy, Presentation of EcoRails Consortia Meeting, 20 January 2011, Budapest, Hungary.

Marchand, B. 1973. Deformation of a transportation surface, $A n$ nals of the Association of American Geographers 63(4): 507521. http://dx.doi.org/10.1111/j.1467-8306.1973.tb00944.x 
Muller, J.-C. 1978. The mapping of travel time in Edmonton, Alberta, The Canadian Geographer / Le Géographe Canadien 22(3): 195-210.

http://dx.doi.org/10.1111/j.1541-0064.1978.tb01012.x

Niederoest, J. 2002. Landscape as a historical object: 3D reconstruction and evaluation of a relief model from the 18th century, The International Archives of the Photogrammetry, Remote Sensing and Spatial Information Sciences 34(5). 7 p. Available from Internet: http://www.isprs.org/proceedings/ XXXIV/5-W3/download/jana.pdf

Saalfeld, A. 1985. A fast rubber-sheeting transformation using simplicial coordinates, The American Cartographer 12(2): 169-173. http://dx.doi.org/10.1559/152304085783915072

Shimizu, E.; Fuse, T.; Shirai, K. 1999. Development of GIS integrated historical map analysis system, The International Archives of the Photogrammetry, Remote Sensing and Spatial Information Sciences 32(5): 79-84.

Tobler, W. D. 1961. Map Transformations of Geographic Space. A thesis submitted in partial fulfilment of the requirements for the degree of doctor of philosophy. University of Washington. $114 \mathrm{p}$.

White, M. S.; Griffin, P. 1985. Piecewise linear rubber-sheet map transformation, The American Cartographer 12(2): 123-131. http://dx.doi.org/10.1559/152304085783915135 